\title{
Optimisation Design of a Taguchi-Based Real-Code Genetic Algorithm for Thermal Reducing of Air-Core Linear Brushless Permanent Magnet Motor
}

\author{
W. J. Chen, J. R. Lin, D. C. Chen, and F. L. Nian
}

\begin{abstract}
This study combined the Taguchi method with the genetic algorithm (GA) to analyse the optimal design parameters of the thermal distribution in an air-core linear brushless permanent magnet motor (ALBPMM). First, this study adopted an $L 18(21 \times 37)$ orthogonal array to determine the significant factors, including active currents, the length of magnets, pole distance of magnets, air-gap length, and thickness and width of coils. Then, the study uses response surface methodology (RSM) to construct the predictive model. Finally, the optimal combinations of design parameters that involve using real-code GA were obtained and verified by finite element modelling. The simulation results show that the thermal distribution in the optimal design of parameters is $41 \%$ more effective than that of any models in which the parameters are not optimised. Therefore, the proposed approach can be used as the basis for designing and predicting the temperature effects of the ALBPMM.
\end{abstract}

Index Terms-Taguchi, genetic algorithm, air-core linear brushless permanent magnet motor, response surface methodology.

\section{INTRODUCTION}

In recent years, linear motors have been widely used in the demand for high-speed and linear motion applications that can raise production efficiency, including electrical, electronic, and mechanical and automation industries [1]. Among all linear motors, the air-core linear brushless permanent magnet motor (ALBPMM) works with no cogging force and exhibits simple structures and a low failure rate [2]. Thus, it has been increasingly used in light-load, high-dynamic-response, and high-stability machines [3]. However, the air-core linear motors demonstrate poor heat dissipation, compared with other linear motors, because their stator is constructed in a U-shaped channel for embedding the mover. If the problems of poor dissipation are not solved, then thermal stress would lead to inaccuracy and instability of linear motors [4]. Above all, the thermal strain generated by thermal stress is the main cause of the inaccuracy and deformation of linear motors [5]. Therefore, the linear motors that undergo proper cooling system can produce $50 \%$ more energy than those without cooling can [6], but thus increasing the additional complex cooling feedback systems. In general, to simplify the thermal analysis model of air-core linear motors, most researchers use thermal resistance models to

Manuscript received May 30, 2014; revised July 20, 2014

The authors are with the Department of Industrial Education and Technology, National Changhua University of Education, Taiwan (e-mail: wjong@cc.ncue.edu.tw) simplify cooling systems for obtaining the equivalent analysis mode. However, the deviation of the analytical results can be increased considerably [7] even though the heat resistance models can quickly estimate thermal performance.

Therefore, some researchers have developed many improvements for the cooling systems of air-core linear motors. Huang [8] et al., used 3D finite element analysis (FEA) to establish the heat transfer analysis models of air-core linear synchronous motor. They focused on an analytical model to perform steady and transient FEA on the heat analysis of motors. Huang [9] et al., conducted heat flow analysis on air-core linear motors, calculating the coefficient of thermal convection to improve the modelling result of coil windings. They used FEA on this model to simulate the thermal field of motors. Li [10] et al., used the optimal design of air-core permanent linear motors to create and analyse the thermal fields of motors. An [11] et al., used the optimal design of air-core linear motors to analyse the effect of current density and the thickness of the coils on a heat transfer model. In addition, Rovers [12] et al., studied the cooling sheet materials of air-core linear motors, winding the coil and assembling sheet materials as an apparatus of reducing temperature distributions. Pan [13] et al., designed a cooling plate in the slot of air-core linear motors, which can avert the eddy current and thus reducing the heat losses of the motor. Therefore, to reduce the temperature of the motor body, the optimal design methods of the parameter conditions of the motor must be provided. Generally, by using traditional optimal methods, the discontinuity distribution of objective function leads to local optimal solution or early convergence. Therefore, in this paper we adopted a Taguchi method and analysis of variance (ANOVA) to determine the significant parameters affecting the temperature distribution of a motor and used response surface methodology (RSM) to establish a mathematical prediction model. Finally, we used the real-code genetic algorithm to determine the optimal parameter combination and optimal temperature distribution of the ALBPMM.

\section{GEOMETRY OF LINEAR MOTORS}

In this study, the stator structure of the ALBPMM comprised bilateral permanent magnets arranged in a U-shaped channel with permanent magnets fixed on the stator in a polar-staggered arrangement to prevent magnetic leakage and maximize the use of the magnetic flux. In addition to the parameters of the controlling system, the 
significant parameters affecting the motor's temperature distribution include the geometries and dimensions of the stator and mover. Fig. 1 presents the topography of the air-core linear motor.

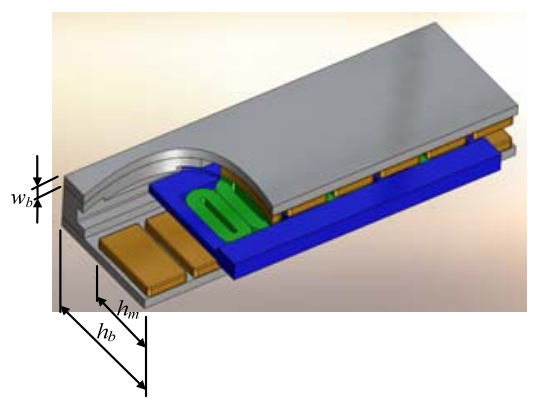

(a)

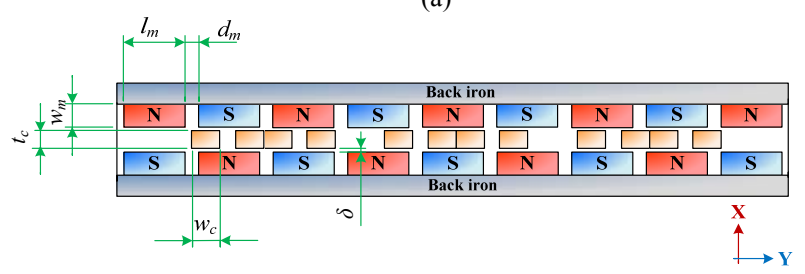

(b)

Fig. 1. (a) The three-dimensional model of ALBPMM (b) Design parameters of ALBPMM.

\section{2D THERMAL ANALYSIS OF LINEAR MOTOR}

Because of the special structure of the ALBPMM and corresponding electromagnetic generation process, performing a thermal analysis on it is more difficult than doing so on a rotary motor. The thermal field of ALBPMM is a complex heat conduction problem. Thus, to analyse the steady heat field of the motor, the homogeneous materials are assumed and the two-dimensional diffusion equations are derived from the theory of heat transfer and Fourier's law of heat conduction in (1).

$$
k\left(\frac{\partial^{2} T}{\partial x^{2}}+\frac{\partial^{2} T}{\partial y^{2}}\right)+\dot{g}=\rho C \frac{\partial T}{\partial t}=0
$$

where $T$ is temperature, $\dot{g}$ is the rate of energy generated per unit volume, $k$ is thermal conductivity, $C$ is the specific heat capacity, and $\rho$ is the density of materials. Because the effect of heat transfer by radiation is not significant in the motor, only the heat transfer by conduction and convection is considered. The initial and boundary conditions are expressed as

$$
\begin{aligned}
& T(x, y, 0)=T_{0}(x, y) \\
& \left.k(\nabla T \cdot \vec{n})\right|_{\left(n_{x}, n_{y}\right)}=h\left(T_{0}-T_{\infty}\right) \\
& \left.k(\nabla T \cdot \vec{n})\right|_{\left(n_{x,}, n_{y}\right)}=\dot{q}
\end{aligned}
$$

Formulation (2) represents the initial condition, formulation (3) represents the convection boundary of the surface of the epoxy, permanent magnet and back-iron of the motor, and formulation (4) represents the boundary condition at the contact surface. In formulation (3), $h$ is the coefficient of convection, $\mathrm{T}_{0}$ and $\mathrm{T} \infty$ are the temperature of convection boundary surface and environmental temperature respectively, and $n_{x}$ and $n_{y}$ are the direction cosines of exterior normal along boundary line.

\section{Magnetic Thermal Coupling Finite Element ANALYSIS OF THE MOTOR}

The COMSOL 4.2 finite element software is used to simulate the temperature distribution of ALBPMM by coupling the models of magnetic fields and heat transfer. In the analysis process, the magnetic field models and boundary conditions are set first, and the results from the magnetic analysis are then coupled to the heat transfer model. The flowchart of the magnet-thermal coupling is shown in Fig. 2. The original parameters of motor are described in Table I.

\begin{tabular}{|c|c|c|c|}
\hline Parameter & Symbol & Unit & Value \\
\hline Air-gap length & $\delta$ & $\mathrm{mm}$ & 0.6 \\
\hline Number of phases & $m$ & & 3 \\
\hline Magnet height & $h_{m}$ & $\mathrm{~mm}$ & 30 \\
\hline Magnet width & $w_{m}$ & $\mathrm{~mm}$ & 3 \\
\hline Magnets of pole distance & $d_{m}$ & $\mathrm{~mm}$ & 5 \\
\hline Magnet length & $l_{m}$ & $\mathrm{~mm}$ & 14 \\
\hline Coil thickness & $t_{c}$ & $\mathrm{~mm}$ & 3.5 \\
\hline Coil width & $w_{c}$ & $\mathrm{~mm}$ & 4 \\
\hline Back iron height & $h_{b}$ & $\mathrm{~mm}$ & 66 \\
\hline Back iron width & $w_{b}$ & $\mathrm{~mm}$ & 4 \\
\hline $\begin{array}{l}\text { Electrical conductivity of the } \\
\text { copper coil }\end{array}$ & $\sigma_{c}$ & $\mathrm{~S} / \mathrm{m}$ & $5.99 \times 10^{7}$ \\
\hline $\begin{array}{l}\text { Electrical conductivity of the } \\
\text { back iron }\end{array}$ & $\sigma_{b}$ & $\mathrm{~S} / \mathrm{m}$ & $1.03 \times 10^{7}$ \\
\hline $\begin{array}{l}\text { Relative permeability of the } \\
\text { back iron }\end{array}$ & $\mu_{r}$ & & 2000 \\
\hline $\begin{array}{l}\text { Br curve of the Permanent } \\
\text { magnet }\end{array}$ & & $T$ & 1.23 \\
\hline $\begin{array}{l}\text { Current density of the } \\
\text { magnetic field }\end{array}$ & $J$ & $\mathrm{~A} / \mathrm{mm}^{2}$ & 3.58 \\
\hline
\end{tabular}

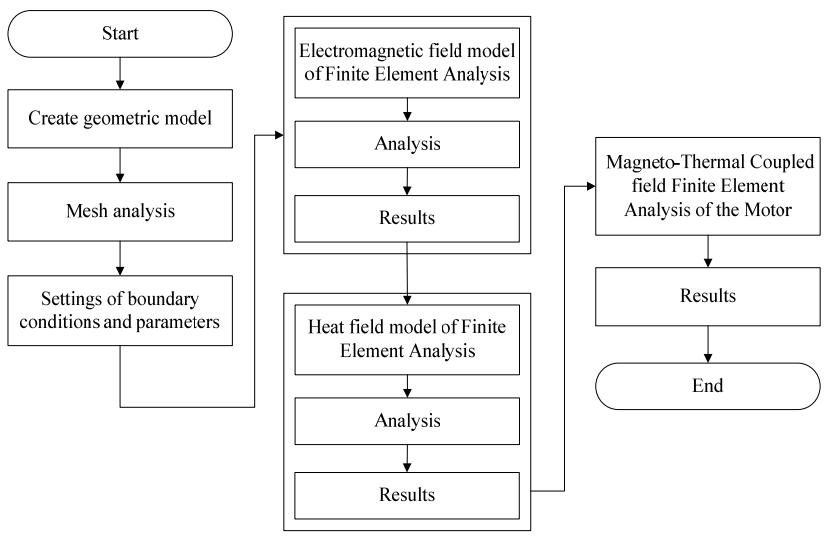

Fig. 2. The flowchart of magnet-thermal coupling analysis.

TABLE I: THE SETTINGS OF PARAMETERS

The magnetic analysis in Fig. 3(a) is conducted using the symmetry planes to reduce the cost of simulation. The current setting is sine wave, in which the current value is based on the position of the mover. The three-phase A-B-C coils modelling are used in this work. Therefore, the current and back-EMF are sinusoidal with $120^{\circ}$ degrees phase shift. When phase " $A$ " faces the magnetic pole, the current is zero; only phases " $\mathrm{B}$ " and " $\mathrm{C}$ " have current flowing through them. The positive and negative directions represent those of the current. After setting the required boundary conditions and 
parameters, finite element mesh analysis is performed; the number of grid nodes of mesh was 6550 as shown in Fig. 3(b).

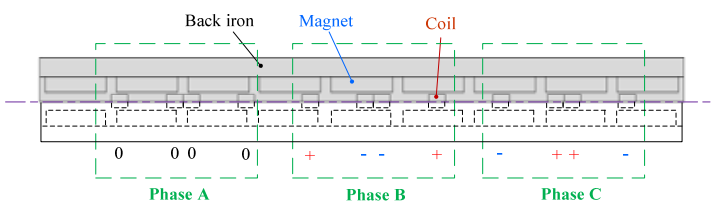

(a)

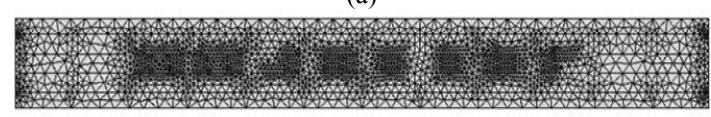

(b)

Fig. 3. (a) The geometrical structure of magnetic analysis (b)The finite element of mesh analysis.

\section{TAguchi-BASED Genetic AlgORIthM}

\section{A. Taguchi Method and ANOVA}

Taguchi methods [14] mainly transform quality characteristics into a signal-to-noise $(S / N)$ ratio, to measure the quality of the product. It is used to reveal the extents of the influence of production or product quality and its error factors. The $S / N$ ratio can reveal the optimal design in which the variance is low and the quality characteristics are fair. The choice of quality characteristics can directly affect product quality. Thus, the $S / N$ ratio is the indicator for evaluating quality. Its main function is to evaluate the stability of the process of production; the higher the $S / N$ ratio is, the smaller the variance of the quality characteristics is and the more favourable the condition. In this study, the $S / N$ ratio values corresponding to the conversions were calculated, using the smaller-the-better (STB) quality characteristics for obtaining the temperature response. The $S / N$ ratio was calculated according to the following (5).

$$
S / N(d B)=-10 \log \frac{1}{n} \sum_{i=1}^{n} y_{i}^{2}
$$

where $y_{i}$ is the temperature value for the experimental results and $n$ is the number of tests in a trial.

After the $S / N$ ratio of each factor is computed, an analysis of variance (ANOVA) is used to yield the relative importance and influence of each parameter to the optimal objectives. The results include the sum of squares, degrees of freedom, variance, contribution, $\mathrm{F}$ values, and confidence level. The purpose of this method is to determine the significance of each factor, and the significant factors can serve as the optimal design factors for designing the prediction models and analysing the target value of the objectives.

\section{B. Response Surface Methodology}

Response surface methodology [15] is also called "regression design". Its purpose is mainly to find the optimal response and mathematical prediction models within specified ranges of each factor. In this study, the central composite design (CCD) in RSM was used, and the optimal predictive model was yielded using second-order polynomial functions, as shown in (6).

where $y$ is the response parameter, $x$ is the design parameters, $s$ is the number of design parameters, $\beta_{0}$ is the constant term, $\beta_{a}$ is the first-order coefficients, $\beta_{a a}$ is the coefficients of the quadratic parameters, $\beta_{a b}$ is the coefficients of the interaction parameters.

$$
y=\beta_{0}+\sum_{a=1}^{s} \beta_{a} x_{a}+\sum_{a=1}^{s} \sum_{b>i}^{s} \beta_{a b} x_{a} x_{b}+\sum_{a=1}^{s} \beta_{a a} x_{a}^{2}
$$

\section{Real-Code Genetic Algorithm}

Genetic algorithm (GA) is a random search method based on an optimized search mechanism for imitating biospheric natural selection. A real-code GA represents parameters with real numbers used in the duration of the entire algorithm processes. Since there are no encoding and decoding operations, the computation time is faster compared with other kinds of genetic algorithms [16]. Therefore, this work applied a real-code GA to solve the optimization problem of the thermal model by combining the design parameters in the ALBPMM. The following lists the steps in using the real-code GA:

Step 1: Initalize the population. Set the maximum number of generations, number of groups, number of design variables, limits of parameters and conditions. The real-code GA manipulates the combination of design parameters used in vector modes, as shown in (7) and (8).

$$
\begin{array}{r}
I_{d}=\left(G_{1}, \ldots, G_{c}\right), d=1, \ldots, N, c=1, \ldots, 6 \\
G_{c}=U_{\max c}+r_{c}\left(U_{\max c}-U_{\min c}\right)
\end{array}
$$

where $I$ is the number of each generation and $G_{c}$ is design parameters between upper limits $U_{\max c}$ and lower limits $U_{\min c}$,

\begin{tabular}{|c|c|c|c|c|c|}
\hline Factor & & Unit & Level 1 & Level 2 & Level 3 \\
\hline$A$ & Current & $A$ & 2 & 6 & \\
\hline$B$ & $\begin{array}{l}\text { Length of } \\
\text { magnets }\end{array}$ & $\mathrm{mm}$ & 13 & 14 & 16.6 \\
\hline$C$ & $\begin{array}{l}\text { Width of } \\
\text { magnets }\end{array}$ & $\mathrm{mm}$ & 3 & 4 & 5 \\
\hline$D$ & $\begin{array}{l}\text { Pole distance } \\
\text { of magnets }\end{array}$ & $\mathrm{mm}$ & 1 & 3 & 5 \\
\hline E & $\begin{array}{l}\text { Air-gap } \\
\text { length }\end{array}$ & $\mathrm{mm}$ & 0.3 & 0.45 & 0.6 \\
\hline$F$ & $\begin{array}{l}\text { Thickness of } \\
\text { coil }\end{array}$ & $\mathrm{mm}$ & 2 & 3.5 & 5 \\
\hline$G$ & Width of coil & $\mathrm{mm}$ & 3 & 4 & 5.5 \\
\hline$H$ & $\begin{array}{l}\text { Wire } \\
\text { diameter }\end{array}$ & $\mathrm{mm}$ & 0.3 & 0.6 & 0.7 \\
\hline
\end{tabular}
$r_{c}$ is a random number within $[0,1]$ and $c$ is the number of design parameters.

TABLE II: DESIGN VARIABLES aND THEIR CODED LEVELS

Step 2: Evaluate the fitness of all individuals in the generation according to the fitness value. The fitness function is the objective function of the optimal problem. Different types of problem have different definitions of fitness function to determine the fitness value.

Step 3: Select and reproduce the chromosomes. In the GA, through selection and reproduction, unfavourable chromosomes (individuals) can be eliminated and favourable ones can be conserved. After iterative computation, the result gradually converges to a certain value, representing the most favourable chromosome determined.

Step 4: Perform the crossover. The purpose of crossover is 
to ensure that individuals with high fitness develop high selectivity. This study used the crossover probability of $60 \%$. When the randomly generated number within $[0,1]$ is less than the set crossover rate, the crossover process is performed.

Step 5: Operate the mutation. The purpose of mutation is to avoid premature convergence and trapping into local optimal solution in search space. If the randomly generated number within $[0,1]$ is less than the set rate of mutation, the mutation operation is performed. The design parameter is multiplied by a random value between 0 and 1 to ensure that every individual is mutated.

Step 6: Determine the stop conditions. The algorithm is terminated when the maximum number of generations is reached. If not, using the algorithm is continued.

TABLE III: L18(21×37) ORTHOGONAL ARRAY

\begin{tabular}{lllllllllllll}
\hline \hline & & & & & & & \multicolumn{7}{c}{ No. of experiments } & $\bar{y}_{k}$ & $\mathrm{~S} / \mathrm{N}(\mathrm{dB})$ \\
\hline 1 & 1 & 1 & 1 & 1 & 1 & 1 & 1 & 1 & 34.33 & 34.33 & 34.328 & -30.714 \\
2 & 1 & 1 & 2 & 2 & 2 & 2 & 2 & 2 & 21.28 & 21.27 & 21.272 & -26.557 \\
3 & 1 & 1 & 3 & 3 & 3 & 3 & 3 & 3 & 21.02 & 21.02 & 21.018 & -26.452 \\
4 & 1 & 2 & 1 & 1 & 2 & 2 & 3 & 3 & 20.73 & 20.72 & 20.722 & -26.329 \\
5 & 1 & 2 & 2 & 2 & 3 & 3 & 1 & 1 & 51.96 & 51.95 & 51.952 & -34.313 \\
6 & 1 & 2 & 3 & 3 & 1 & 1 & 2 & 2 & 20.94 & 20.94 & 20.941 & -26.421 \\
7 & 1 & 3 & 1 & 2 & 1 & 3 & 2 & 3 & 20.99 & 20.98 & 20.984 & -26.438 \\
8 & 1 & 3 & 2 & 3 & 2 & 1 & 3 & 1 & 20.50 & 20.50 & 20.497 & -26.234 \\
9 & 1 & 3 & 3 & 1 & 3 & 2 & 1 & 2 & 41.36 & 41.36 & 41.358 & -32.332 \\
10 & 2 & 1 & 1 & 3 & 3 & 2 & 2 & 1 & 31.81 & 31.81 & 31.807 & -30.051 \\
11 & 2 & 1 & 2 & 1 & 1 & 3 & 3 & 2 & 27.92 & 27.92 & 27.921 & -28.919 \\
12 & 2 & 1 & 3 & 2 & 2 & 1 & 1 & 3 & 188.95 & 188.90 & 188.924 & -45.526 \\
13 & 2 & 2 & 1 & 2 & 3 & 1 & 3 & 2 & 24.90 & 24.89 & 24.894 & -27.922 \\
14 & 2 & 2 & 2 & 3 & 1 & 2 & 1 & 3 & 228.01 & 228.00 & 228.005 & -47.159 \\
15 & 2 & 2 & 3 & 1 & 2 & 3 & 2 & 1 & 37.35 & 37.35 & 37.351 & -31.447 \\
16 & 2 & 3 & 1 & 3 & 2 & 3 & 1 & 2 & 356.44 & 356.40 & 356.419 & -51.040 \\
17 & 2 & 3 & 2 & 1 & 3 & 1 & 2 & 3 & 29.02 & 29.02 & 29.020 & -29.255 \\
18 & 2 & 3 & 3 & 2 & 1 & 2 & 3 & 1 & 26.11 & 26.11 & 26.108 & -28.336 \\
\hline All results average & $\bar{y}$ & & & & & & & & 66.862 & -31.969 \\
\hline \hline
\end{tabular}

\begin{tabular}{llllllll}
\multicolumn{7}{c}{ TABLE VI: RESULTS OF ANOVA } \\
\hline \hline Factor & DOF & Sum of Sqrs & Variance & F-Ratio & Confidence & $\rho \%$ & Significant \\
\hline B & 1 & 54037.636 & 54037.636 & 228.349 & $100 \%$ & 18.283 & Yes \\
C & 2 & 6979.732 & 3489.866 & 14.747 & $99.9 \%$ & 2.361 & Yes \\
D & 2 & 4177.974 & 2088.987 & 8.827 & $99.8 \%$ & 1.414 & No \\
E & 2 & 41935.709 & 20967.854 & 88.604 & $100 \%$ & 14.188 & Yes \\
F & 2 & 33944.377 & 16972.188 & 71.720 & $100 \%$ & 11.484 & Yes \\
G & 2 & 19868.441 & 9934.220 & 41.979 & $100 \%$ & 6.722 & Yes \\
H & 2 & 124974.401 & 62487.200 & 264.055 & $100 \%$ & 42.283 & Yes \\
Error & 20 & 4916.360 & 2458.180 & 10.387 & $99.9 \%$ & 1.663 & No \\
Total & 35 & 2952.884 & 236.644 & $*$ NOTE: At least $99.9 \%$ confidence & & \\
\hline \hline
\end{tabular}

VI. Optimal Design And Process of AlbPMm

\begin{tabular}{|c|c|c|c|c|c|}
\hline \multicolumn{2}{|c|}{$\begin{array}{l}\text { Design } \\
\text { variables level }\end{array}$} & \multirow{2}{*}{$\frac{\text { Unit }}{\mathrm{A}}$} & \multirow{2}{*}{$\frac{-1}{1.5}$} & \multirow{2}{*}{$\frac{0}{2}$} & \multirow{2}{*}{$\frac{-1}{2.5}$} \\
\hline$x_{1}$ & Current & & & & \\
\hline$x_{2}$ & $\begin{array}{l}\text { Length of } \\
\text { magnets }\end{array}$ & $\mathrm{mm}$ & 11 & 13 & 15 \\
\hline$x_{3}$ & $\begin{array}{l}\text { Pole } \\
\text { distance } \\
\text { of } \\
\text { magnets }\end{array}$ & $\mathrm{mm}$ & 4 & 5 & 6 \\
\hline$x_{4}$ & $\begin{array}{l}\text { Air-gap } \\
\text { length }\end{array}$ & $\mathrm{mm}$ & $\begin{array}{l}0.3 \\
5\end{array}$ & $\begin{array}{l}0.4 \\
5\end{array}$ & $\begin{array}{l}0.5 \\
5\end{array}$ \\
\hline$x_{5}$ & $\begin{array}{l}\text { Thickness } \\
\text { of coil }\end{array}$ & $\mathrm{mm}$ & 2.5 & 3.5 & 4.5 \\
\hline$x_{6}$ & $\begin{array}{l}\text { Width of } \\
\text { coil }\end{array}$ & $\mathrm{mm}$ & 2 & 3 & 4 \\
\hline
\end{tabular}

This study used a Taguchi-based real-code GA on the optimizing parameter design of the thermal analysis of the ALBPMM. Fig. 5 shows the research flowchart in this work.

The steps of this process are listed as follows:

Step 1: Use an $L_{18}\left(2^{1} \times 3^{7}\right)$ orthogonal array, including eight controlled factors as the Taguchi method design parameters. As shown in Table II, Factor " $A$ " is set at two levels, and the remaining factors are set at three levels.

Step 2: Select the quality characteristic of STB and perform 18 sets of experiments involving different factor combinations on the orthogonal array. The finite element analysis software COMSOL is used to analyse the thermal-magnetic couple of the motor and calculate the temperature distribution. All the experimental data and $\mathrm{S} / \mathrm{N}$ ratio are listed in Table III. 


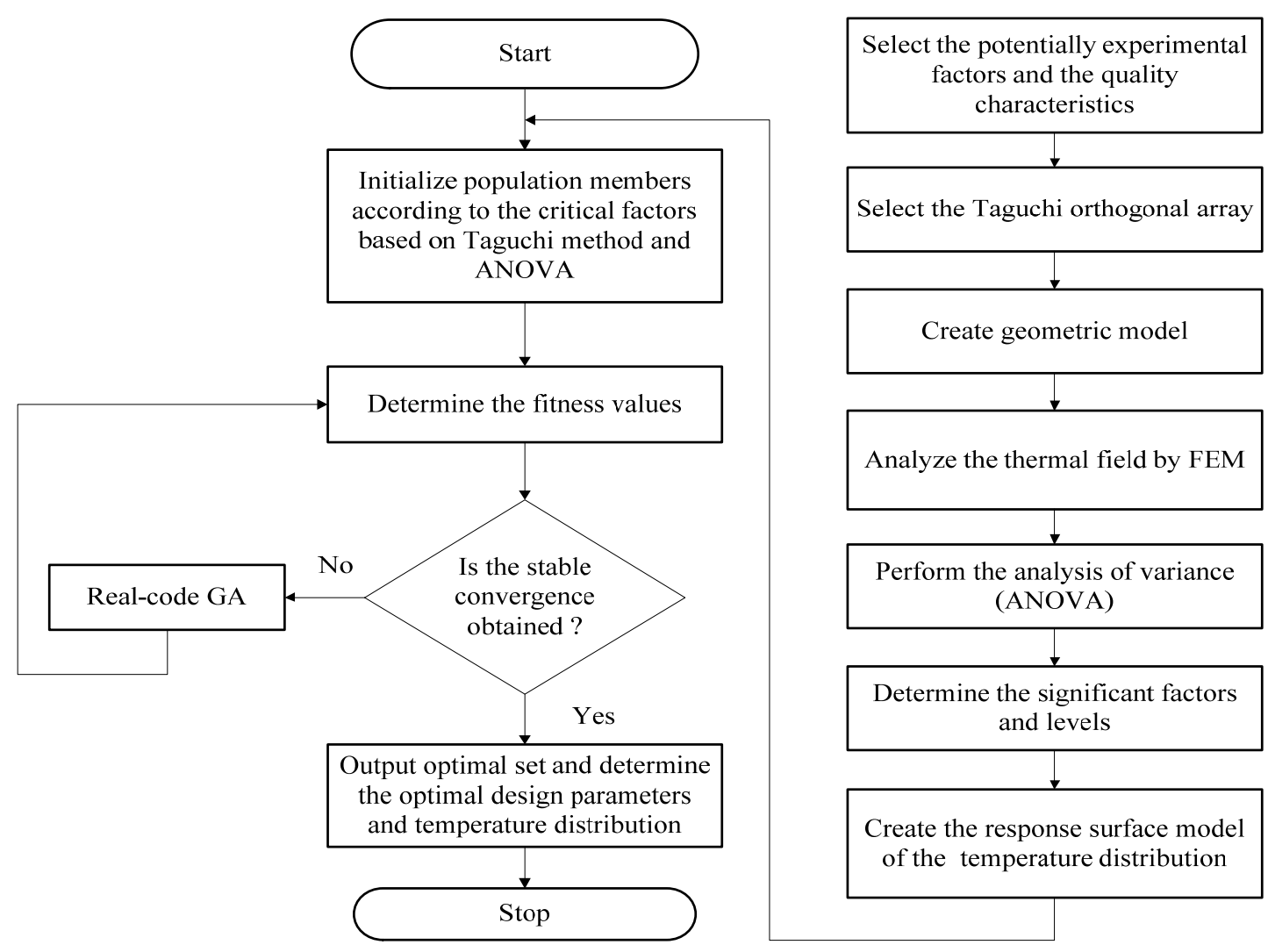

Fig. 5. The flowchart of the ALBPMM optimization design.

Step 3: Use ANOVA to obtain the variation effect on the quality of each factor to determine the most significant factors in the entire experiment, as shown in Table IV.

Step 4: Establish mathematical predictive models by using $\mathrm{RSM}$. The temperature distribution of the motor is selected as the quality characteristic of the RSM. Its parameters are shown in Table V.

Step 5: Run 31 experiments and use quadratic regression equations to establish the interaction among significant factors to obtain the mathematical predictive model of the objective. The result is shown in (9).

$$
\begin{aligned}
& f_{T}=23.293+0.7948 x_{1}-0.0176 x_{2} \\
& +0.0013 x_{3}+0.0171 x_{4}+0.0907 x_{5} \\
& +0.2183 x_{6}+0.0517 x_{1}{ }^{2}-0.0011 x_{2}{ }^{2} \\
& -0.0111 x_{3}{ }^{2}-0.0017 x_{4}{ }^{2}-0.0186 x_{5}{ }^{2} \\
& -0.0008 x_{6}{ }^{2}+0.0142 x_{1} x_{2}-0.018 x_{1} x_{3} \\
& -0.0145 x_{1} x_{4}+0.0404 x_{1} x_{5}+0.0716 x_{1} x_{6} \\
& -0.0227 x_{2} x_{3}-0.0269 x_{2} x_{4}+0.013 x_{2} x_{5} \\
& +0.0267 x_{2} x_{6}+0.0234 x_{3} x_{4}-0.032 x_{3} x_{5} \\
& -0.0207 x_{3} x_{6}-0.0239 x_{4} x_{5}-0.0224 x_{4} x_{6} \\
& +0.0266 x_{5} x_{6}
\end{aligned}
$$

Step 6: Use the real-code GA to conduct iterative computation on every iterative selection, reproduction, crossover, and mutation. Use roulette wheel selection and the flat crossover [17] technique to set the rate probability of at $60 \%$ and set the mutation rate at $10 \%$.
Step 7: Evaluate whether reaching the optimal condition.

Step 8: Determine the combination of optimal parameters from parameter space, and analyse the thermal distribution of ALBPMM to confirm the result.

\section{THE RESUlTS AND ANALYSIS OF EXPERIMENT}

\section{A. Factor Changes to the S/N Ratio Affect Taguchi Method Analysis}

Table VI shows the response table of each factor. The $\mathrm{S} / \mathrm{N}$ ratios of each factor appear at different levels because of the average value corresponding to the 18 combination sets appearing at the same level. When the quality characteristic is the STB, the $\mathrm{S} / \mathrm{N}$ ratio is negative. The closer to zero the $\mathrm{S} / \mathrm{N}$ ratio approaches, the more favourable the quality characteristic is. According to the response table and figure of each factor corresponding to the $\mathrm{S} / \mathrm{N}$ ratio, a set of the most favorable combination of factors can be found. Ensuring that the $\mathrm{S} / \mathrm{N}$ ratio approaches zero requires using the combination $A_{2} B_{3} C_{1} D_{3} E_{2} F_{3} G_{1} H_{3}$.

Table III lists the results calculated using ANOVA at a confidence level of $99.9 \%$ for the smallest $F(0.01,2,18)=$ 10.39; hence, the significant factors are Factors A, B, D, E, F, $\mathrm{G}$ and $\mathrm{H}$. Among these factors, Factor $\mathrm{H}$ is the wire diameter interacting in the active current with Factor A. If Factor $\mathrm{H}$ is also used as a significant parameter, then the current density would be affected. Therefore, the significant factors are Factors $A, B, D, E, F$, and $G$.

\section{B. Verification Taguchi Method}

After using the Taguchi methods and ANOVA to 
determine the significant design factors and target value, the design values should be confirmed. The goal is to predict the quality characteristics of new design values and to determine whether the quality is improved. In order to confirm the

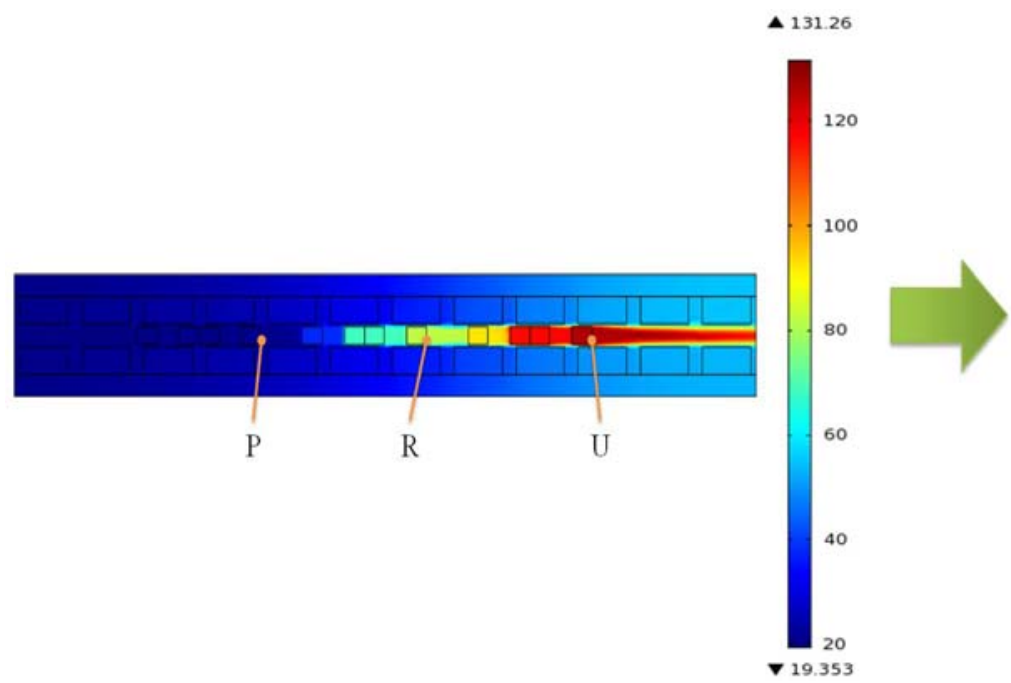

(a)

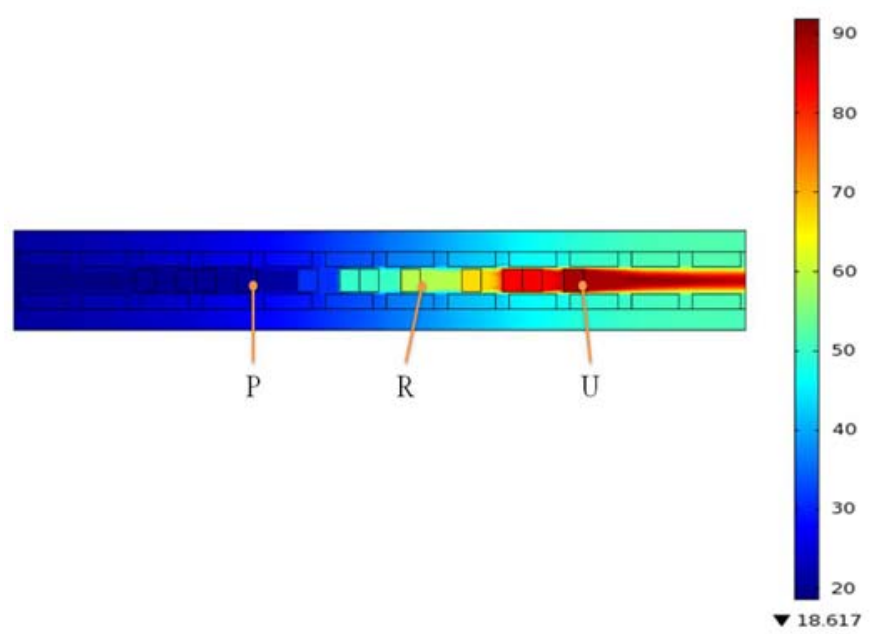

$\Delta 91.704$

(b)
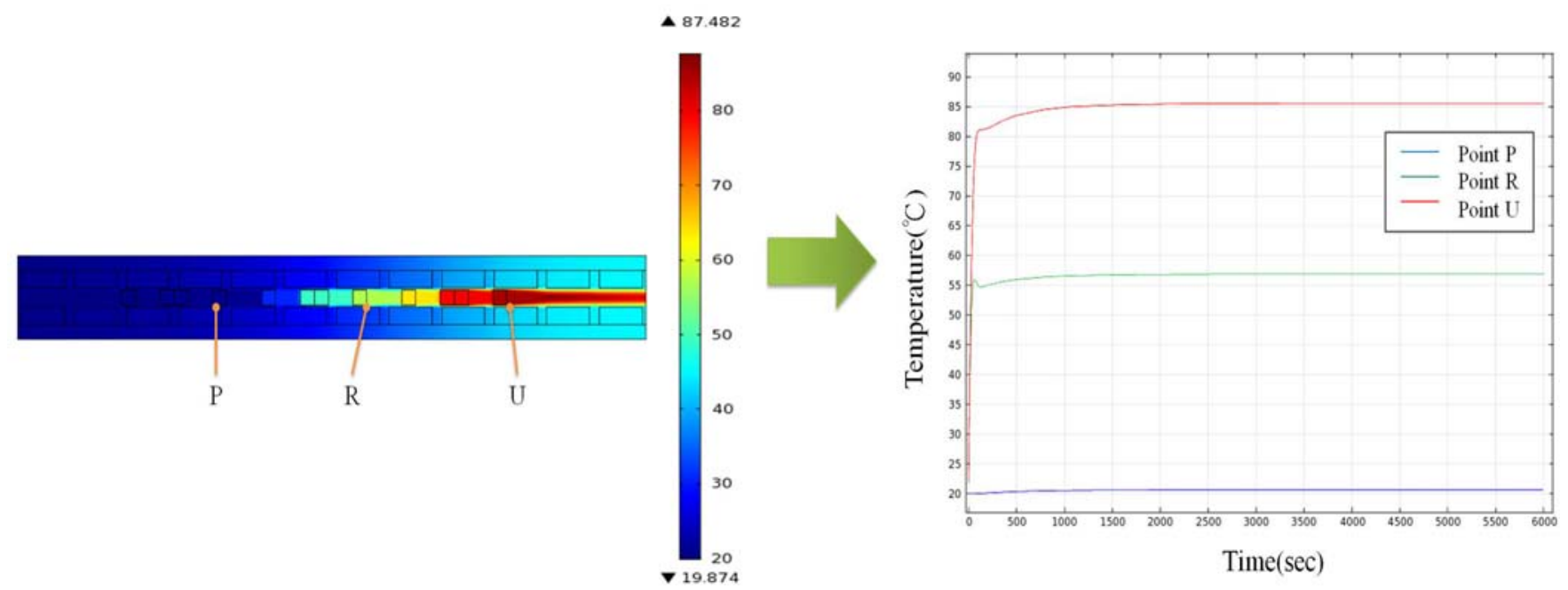

(c)

Fig. 6. (a) The non-optimal model temperature of temperature distribution and each point of temperature curve. (b)The Taguchi method model temperature of temperature distribution and each point of temperature curve. (c)The optimization model temperature of temperature distribution and each point of temperature curve. 


\section{Optimal Design Parameters Conditions and Temperature Distribution}

After a central composite design (CCD) in RSM mathematical model was constructed, using the real-code GA led to the optimal parameter combination. The Taguchi-based real-code GA can effectively reduce the tempeture of motor. When the curve of Taguchi-based real-code GA converges, its fitness value is at $89.84{ }^{\circ} \mathrm{C}$. Table VII shows that the optimal design parameters of the non-optimized, traditional Taguchi method and Taguchi-based real-code GA through the verification of FEM. The current flows through phase " $\mathrm{C}$ " and the performing time is $6000 \mathrm{~s}$. The difference value is about $2{ }^{\circ} \mathrm{C}$ compared with the result of Taguchi-based Real-code GA. Fig. 6 (a)-(b) shows the temperature distributions of $P, R$ and $U$ points of motor from non-optimization, traditional Taguchi method and Taguchi-based Real-code GA. The temperatures of $\mathrm{P}, \mathrm{R}$ and $\mathrm{U}$ points in Fig. 6 (a) are $23.49^{\circ} \mathrm{C}, 82.76^{\circ} \mathrm{C}$ and $128.1^{\circ} \mathrm{C}$, respectively. The temperatures of $\mathrm{P}, \mathrm{R}$ and $\mathrm{U}$ points in Fig. 8 (b) and Fig. 6 (c) are $20.90^{\circ} \mathrm{C}, 57.11^{\circ} \mathrm{C}$ and $88.67^{\circ} \mathrm{C}$ and $20.62^{\circ} \mathrm{C}, 56.89^{\circ} \mathrm{C}$ and $85.59^{\circ} \mathrm{C}$, respectively. Obviously the temperature distribution of motor can be effectively reduced through the Taguchi-based Real-code GA.

TABLE VI: RESPONSE TABLE OF FACTORS VIA S/N RATIO (UNIT: dB)

\begin{tabular}{lllllllll}
\hline & $\mathrm{A}$ & $\mathrm{B}$ & $\mathrm{C}$ & $\mathrm{D}$ & $\mathrm{E}$ & $\mathrm{F}$ & $\mathrm{G}$ & $\mathrm{H}$ \\
\hline Level 1 & -28.421 & -31.012 & -32.082 & -29.833 & -31.331 & -30.182 & -40.181 & -31.370 \\
Level 2 & -35.517 & -31.794 & -32.073 & -31.515 & -34.522 & -32.198 & -28.361 & -32.265 \\
Level 3 & & -33.101 & -31.752 & -34.56 & -30.054 & -33.527 & -27.366 & -32.272 \\
Effect & 7.09 & 2.08 & 0.33 & 4.73 & 4.467 & 3.345 & 12.814 & 0.901 \\
\hline \hline
\end{tabular}

TABLE VII: COMPARISONS OF NON-OPTIMISED, TAGUCHI METHOD, TAGUCHI MECHED AND OPTIMISATION MODEL

\begin{tabular}{llllllll}
\hline Design parameters & $\mathrm{A}$ & $\mathrm{B}$ & $\mathrm{D}$ & $\mathrm{E}$ & $\mathrm{F}$ & $\mathrm{G}$ & $\mathrm{T}\left({ }^{\circ} \mathrm{C}\right)$ \\
\hline Non-optimised & 6 & 14 & 5 & 0.6 & 3.5 & 4 & $131.26^{\circ} \mathrm{C}$ \\
Taguchi method & 6 & 16.6 & 5 & 0.45 & 5 & 3 & $91.704^{\circ} \mathrm{C}$ \\
Optimization model & 1.5 & 14 & 4 & 0.55 & 2.5 & 2 & $87.482^{\circ} \mathrm{C}$ \\
\hline \hline
\end{tabular}

\section{CONCLUSION}

This study combined the Taguchi method, RSM, and a real-code GA to determine the significant design parameters of optimal temperature distribution for the ALBPMM, thereby deriving an ideal result. The result can provide developers with a reference of thermal distribution when designing air-core linear brushless permanent magnet motors. The method proposed by this study can also simplify the methods of prediction in thermal distribution. Thus, developers can reduce the time required for experiments and save costs on materials to improve the operational performance of the ALBPMM.

\section{ACKNOWLEDGMENT}

This work is supported by the Ministry of Science and Technology of Taiwan, R.O.C ( NSC 102-2221-E-018-004-), which is gratefully appreciated.

\section{REFERENCES}

[1] K. Sato, M. Katori, and A. Shimokohbe, "Ultrahigh-acceleration moving-permanent -magnet linear synchronous motor with a long working range," IEEE/ASME Trans. Mechatron., vol. 18, no. 1, pp. 307-315, Feb. 2013.

[2] P. Ma, C. X. Liao, Z. H. Chen, and A. M. Chen, "Dynamic response of the linear motor feed drives with Magneto-rheological fluid damper," in Proc. 2010 International Conference on Mechanic Automation and Control Engineering (MACE), Wuhan, China, pp. 3072-3077, June 26-28, 2010.

[3] L. Y. Li, Y. B. Tang, M. N. Ma, and D. H. Pan, "Analysis and optimization of air-core permanent magnet linear synchronous motors with overlapping concentrated windings for ultra-precision applications," in Proc. 15th International Conference on Electrical Machines and Systems (ICEMS), Sapporo, pp. 1-6, October 21-24, 2012.

[4] J. Jiménez, J. A. Malumbres, I. Elósegui, and M. M. Iturralde, "Coupled electromagnetic and thermal design of miniaturized permanent magnet linear motors for sliding door applications," Int. Rev. Electr. Eng., vol. 8, no. 5, pp. 1416-1426, October 2013.

[5] J. H. Chow, Z. W. Zhong, W. Lin, L. P. Khoo, W. J . Lin, and G. L. Yang, "Investigation of thermal effect in permanent magnet linear motor stage," in Proc. 11th International Conference on Control Automation Robotics \& Vision (ICARCV), Singapore, pp. 258-262, Dec 7-10, 2010.

[6] N. Robert, S. Robert, and B. A. Stephen, "Linear motors: How to beat the heat," Motion System Design, May 2000.

[7] U. S. Andres, G. Almandoz, J. Poza, and A. J. Escalada, "Thermal test procedure and analytical model calibration method for electrical machines," IEEE Workshop on Electrical Machines Design Control and Diagnosis (WEMDCD), Paris, pp. 95-103, March 11-12, 2013.

[8] D. S. Huang, J. S. Shih, H. C. Hsia, and M. T. Lin. (October 2011) Three-Phase linear motor heat transfer analysis using the finite-element method. Heat Trans. Eng. [Online]. Available: http://www.tandfonline.com/doi/abs/10.1080/01457630903425940\#pr eview

[9] X. Z. Huang, J. X. Liu, C. M. Zhang, and L. Y. Li. (May 2013). Calculation and experimental study on temperature rise of a high overload tubular permanent magnet linear motor. [Online]. Available: http://ieeexplore.ieee.org/xpl/articleDetails.jsp?arnumber $=6497648$

[10] L.Y. Li, D. H. Pan, and X. Z. Huang, "Analysis and optimization of ironless permanent magnet linear motor for improving thrust," in Proc. 16th International Symposium on. Electromagnetic Launch Technology (EML), Beijing, pp. 1-4, May 15-19, 2012.

[11] H. J. An, J. H. Kim, K. B. Jang, and G. T. Kim, “Optimal current density with coil thickness of double sided permanent magnet linear synchronous motor (PMLSM)," International Conference on Electrical Machines and Systems (ICEMS), Incheon, pp. 1563-1566, October 10-13, 2010.

[12] J. M. M. Rovers, J. W. Jansen, and E. A. Lomonova, "Disturbance effects of electrically conductive material in the air gap of a linear permanent magnet synchronous motor," IEEE Trans. Magn., vol. 47, no. 10, pp. 2668-2671, October 2011.

[13] D. H. Pan, L.Y. Li, Q. M. Chen, T. C. Wang, and E. Peng, "Eddy current damping suppression of air-core monopole linear motor for nanopositioning system," IEEE Trans. Magn., vol. 49, no. 7, pp. 3957-3960, July 2013.

[14] C. C. Hwang, C. M. Chang, and C. T. Liu, "A Fuzzy-Based Taguchi Method for multiobjective design of PM motors," IEEE Trans. Magn., vol. 49, no. 5, pp. 2153-2156, May 2013.

[15] H. T. Wang, M. R. Elidrissi, K. S. Chan, K. Eason, B. X. Xu, S. J. Greaves, Y. Kanai, and H. Muraoka, "Optimal design of MAMR and 
HAMR by applying response surface methodology," IEEE Trans. Magn., vol. 49, no. 6, pp. 2719-2722, June 2013.

[16] M. Melanie, An Introduction to Genetic Algorithms, MIT Press, Massachusetts, 1999, ch. 5.

[17] F. Herrera, M. Lozano, and J. L. Veroegay, "Tackling Real-Coded Genetic Algorithms: operators and tool for behavioural analysis," Artificial Intell. Rev., vol. 12, no. 4, pp. 265-319, August 1998.

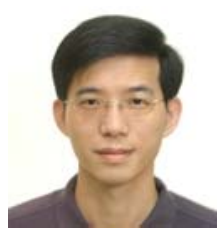

Wen-Jong Chen is an associate professor in the Department of Industrial Education and Technology at National Changhua University of Education (NCUE), Changhua, Taiwan since 2006. He received his M.S. degree in 1994 and Ph.D. (2003) in the Institute of Applied Mechanics and Department of Mechanical Engineering from National Taiwan University, Taipei, Taiwan, respectively. Chen's research areas and interests include control system, artificial intelligent and multi-objective optimization.

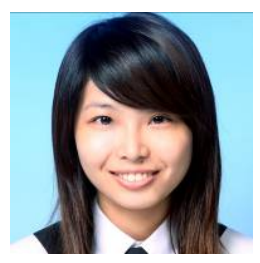

Jia-Ru Lin is currently a graduate student in the Department of Industrial Education and Technology at National Changhua University of Education (NCUE), Changhua, Taiwan. She received her B.S. degree from the Department of Industrial Education and Technology at National Changhua University of Education, Changhua, Taiwan, in 2012. Her research areas and interests consist of $\mathrm{CAD} / \mathrm{CAM}$ and finite-element analysis in linear motor.

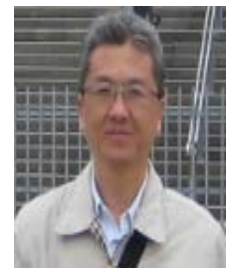

Dyi-Cheng Chen is a professor in the Department of Industrial Education and Technology at National Changhua University of Education. During the school, he did many researches of National Science Council. $\mathrm{He}$ is interested in technological and vocational education, mechanical engineering and material forming areas

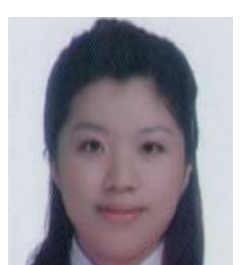

Fung-Ling Nian received the B.S. degree from the Department of Industrial Education and Technology at National Changhua University of Education (NCUE), Changhua, Taiwan. She received her M.S. degree from the Department of Industrial Education and Technology at National Changhua University of Education, Changhua, Taiwan, in 2012. Her research areas and interests include finite-element analysis in linear motor and Engineering Optimization. 